\title{
Use of contrast-enhancement and high-resolution 3D black-blood MR Imaging to identify inflammation in rabbit atherosclerotic plaques
}

\author{
Yoo Jin Hong*, Jin Hur, Jaeseok Park, Young Jin Kim, Hye-Jeong Lee, Byoung Wook Choi, Kyu-Ok Choe
}

From 2011 SCMR/Euro CMR Joint Scientific Sessions

Nice, France. 3-6 February 2011

\section{Background}

Inflammation plays a critical role in plaque initiation, progression, and disruption. As such, inflammation represents an emerging target for the treatment of atherosclerosis.

\section{Purpose}

We investigated the contributing factors for plaque enhancement and examined the relationships between regional contrast enhancement and the inflammatory activity of atherosclerotic plaques in an experimental rabbit model using contrast-enhanced high-resolution 3D black-blood magnetic resonance imaging (MRI) in comparison with histopathology.

\section{Methods}

Ten atherosclerotic rabbits and three normal control rabbits underwent high-resolution 3D contrast-enhanced black-blood MRI. MR images and the corresponding histopathological sections were divided into four quadrants. Plaque composition was analyzed for each quadrant according to histopathological (percent of lipid-rich, fibrous, macrophage area and microvessel density) and imaging criteria (enhancement ratio (ER), $\mathrm{ER}=$ SIpost/SIpre).

\section{Results}

A total of 62 non-calcified plaques ( $\mathrm{n}=248,156$ lipidrich quadrants and 92 fibrous quadrants) were identified based on histopathology. Mean ER values were significantly higher in atherosclerotic vessel walls than in normal vessel walls $(2.03 \pm 0.25$ vs $1.58 \pm 0.15, \mathrm{p}=0.017)$.

Severance hospital, Seoul, Korea, Republic of
Mean ER values were significantly higher in macrophage-rich plaques compared to the macrophage-poor plaques $(2.21 \pm 0.28$ vs $1.81 \pm 0.22, \mathrm{p}=0.008)$. Using multiple regression analysis, macrophage area and microvessel density were independently associated with ER values that reflected plaque enhancement $(p<0.001)$.

\section{Conclusion}

Contrast-enhanced high-resolution 3D black-blood MRI may be an efficient method to predict plaque inflammation.

Published: 2 February 2011

doi:10.1186/1532-429X-13-S1-P22

Cite this article as: Hong et al:: Use of contrast-enhancement and highresolution 3D black-blood MR Imaging to identify inflammation in rabbit atherosclerotic plaques. Journal of Cardiovascular Magnetic Resonance 2011 13(Suppl 1):P22.

Submit your next manuscript to BioMed Central and take full advantage of:

- Convenient online submission

- Thorough peer review

- No space constraints or color figure charges

- Immediate publication on acceptance

- Inclusion in PubMed, CAS, Scopus and Google Scholar

- Research which is freely available for redistribution

Submit your manuscript at www.biomedcentral.com/submit 